\title{
Primacy effect in short-term memory in young children'
}

\author{
MARGARET DONALDSON and \\ HEATHER STRANG, University of Edin- \\ burgh, Edinburgh 8, Scotland
}

Subjects, between the ages of 4 and 7 years, took part in a study of short-term memory. The material was a series of picture cards. The pattern of results for Ss over 5 years approximated that typically found with adults. Among the younger children it appeared initially that no primacy effect was present. However, when allowance was made for position preference, some evidence of a primacy effect was obtained.

In an attempt to devise a valid method of assessing short-term memory in young children, Atkinson et al (1964) used picture cards as material in a serial learning task given to 40 children between the ages of $3 \frac{1}{2}$ and 51/2 in Oakland, California. A series of 32 trials was run. On each trial 8 cards chosen randomly out of a total pool of 11 , depicting animals, were shown one at a time and arrayed face downwards. The $S$ was then required to locate the one matching a given cue card, and was allowed to continue turning up cards until the right one was found. This technique, it was claimed, was capable of holding the interest of even the younger Ss, and allowed orderly data to be obtained.

Analysis of first-choice responses in Atkinson's study did not reveal the trend found in similar studies with adults. While recency of presentation produced the usual marked facilitating effect on memory, no similar primacy effect was noted. This discrepancy was not explained. An observed tendency to select a card in the position just one lower (i.e., more recent) than the one to be located was interpreted according to the assumption that the position of each card was memorized in sequence, with the result that omissions due to forgetting in "counting back" led to choice of a more recent card than the correct one.

$$
\text { METHOD }
$$

It was decided to adopt the procedure outlined above as part of a broader program of research on cognitive development in young children. As the time available was restricted, eight trials only were given. This allowed each of a set of eight pictures, and each position in the array, to be correct on one trial. Each session lasted approximately $10-15 \mathrm{~min}$. The pictures used were cut from a children's book, and showed familiar objects, such as table, fish, apple, etc. These were shown one at a time in random order, and set face downwards in a row before the
Table 1

Frequencies of First Choices for Each Cand Position for Group A.

\begin{tabular}{ccccccccc}
\hline & \multicolumn{6}{c}{ First Position Selected } \\
\cline { 2 - 7 } Correct Position & 1 & 2 & 3 & 4 & 5 & 6 & 7 & 8 \\
\hline 1 & 10 & 1 & 1 & 4 & 0 & 0 & 0 & 0 \\
2 & 2 & 3 & 5 & 2 & 2 & 1 & 1 & 0 \\
3 & 2 & 3 & 1 & 5 & 3 & 2 & 0 & 0 \\
4 & 2 & 3 & 1 & 7 & 2 & 1 & 0 & 0 \\
5 & 0 & 0 & 2 & 7 & 5 & 0 & 0 & 1 \\
6 & 0 & 0 & 1 & 6 & 6 & 1 & 2 & 1 \\
7 & 0 & 0 & 1 & 7 & 5 & 1 & 1 & 1 \\
8 & 0 & 1 & 0 & 6 & 2 & 2 & 1 & 4 \\
Total & 16 & 11 & 12 & 44 & 25 & 8 & 5 & 7 \\
\hline
\end{tabular}

$S$, the card most recently shown being on the S's right.

The instructions were: "I am going to show you some pictures one at a time and then I am going to put them face down on the table. Try to remember where I put each one so that you can find one again when I ask you. Tell me what you see as I show it to you." If the wrong card was turned up the $S$ was encouraged to continue trying till he found the right one.

The test was administered to two groups of Ss. Group A consisted of 16 children (8 boys and 8 girls) from a kindergarten (mean age: 4 years 5 months; SD: 3.0 months). Group B consisted of 110 children ( 55 boys and 55 girls) from the youngest class in each of three different primary (grade) schools

Table 2

Frequencies of First Choices for Each Cand Position for Group B.

\section{First Position Selected}

\begin{tabular}{crrrrrrrrr} 
& \multicolumn{10}{c}{ First Position Selected } \\
\cline { 2 - 9 } Correct Position & 1 & 2 & 3 & 4 & 5 & 6 & 7 & 8 \\
\hline 1 & 97 & 4 & 1 & 2 & 4 & 1 & 0 & 1 \\
2 & 10 & 66 & 6 & 10 & 9 & 4 & 2 & 3 \\
3 & 4 & 22 & 24 & 19 & 23 & 9 & 5 & 4 \\
4 & 2 & 33 & 20 & 26 & 7 & 8 & 4 & 10 \\
5 & 3 & 6 & 14 & 26 & 28 & 12 & 12 & 9 \\
6 & 1 & 1 & 5 & 12 & $\frac{3}{33}$ & 35 & 14 & 9 \\
7 & 2 & 2 & 11 & 14 & 16 & 23 & $\frac{31}{8}$ & 11 \\
8 & 2 & 3 & 3 & 7 & 11 & 7 & $\frac{79}{16}$ \\
Total & 121 & 137 & 84 & 116 & 131 & 99 & 76 & 116 \\
\hline
\end{tabular}

Table 3

Proportion of First Choices for Each Cand Position, and Proportion of These that were Erroneous.

\begin{tabular}{llrrrrrrrr}
\hline & & \multicolumn{7}{c}{ Card Position } \\
Group & \multicolumn{1}{c}{1} & \multicolumn{1}{c}{2} & \multicolumn{1}{c}{3} & \multicolumn{1}{c}{4} & \multicolumn{1}{c}{5} & \multicolumn{1}{c}{6} & \multicolumn{1}{c}{} & \multicolumn{1}{c}{8} \\
\hline A & \% first choices & 12.5 & 8.6 & 9.4 & 34.4 & 19.5 & 6.3 & 3.9 & 5.5 \\
& \% errors & 37.5 & 72.7 & 91.7 & 84.1 & 80.0 & 87.5 & 80.0 & 42.9 \\
B & \% first choices & 13.8 & 15.6 & 9.5 & 13.2 & 14.9 & 11.3 & 8.6 & 13.2 \\
& \% errors & 19.8 & 51.8 & 71.4 & 77.6 & 78.6 & 64.7 & 59.2 & 40.5 \\
1 & \% first choices & 13.8 & 14.6 & 14.3 & 17.6 & 17.1 & 12.9 & 5.6 & 4.2 \\
(Atkinson et al) & \% errors & 19.3 & 35.5 & 52.7 & 62.5 & 66.1 & 78.0 & 66.7 & 37.0 \\
2 & \% first choices & 14.1 & 13.4 & 12.7 & 16.6 & 14.2 & 11.6 & 12.0 & 5.5 \\
(Atkinson et al) & \% errors & 15.6 & 20.9 & 32.1 & 46.2 & 56.0 & 51.4 & 57.1 & 34.6 \\
\hline
\end{tabular}




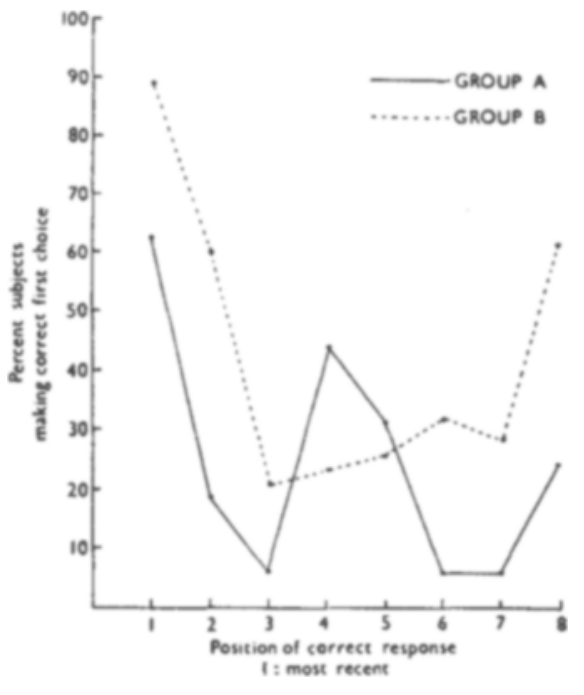

Fig. 1. Percentage of Ss making a correct first choice as a function of the position of the cue card.

of Positions 8 and 2 when Group B is compared with Group $A$, and in the decrease in relative ease of Positions 4 and 5 . The two rank orders are not significantly correlated.

This measure of difficulty, however, takes no account of the absolute frequency with which a given position was selected. Thus it does not allow for the possible effects of a position preference. Table 3 gives the proportion of all first choices that fell on a given card position, and further shows what proportion of these were erroneous, that is, it expresses the error frequency as a proportion of the choice frequency. Table 3 also gives comparable figures calculated for Atkinson's data. Atkinson's younger group is referred to as Group 1, his older group as Group 2.

In Group A, Positions 4 and 5 combined yield $53.9 \%$ of all first choices. A high proportion of these are erroneous (84.1\% for Position 4, 80.0\% for Position 5). Notice, of course, that if more than one-eighth of all choices fall on a given position some of the choices must necessarily be errors, and a very high percentage of choices is incompatible with a very low percentage of errors. However, when the percentage of choices is low, there is no constraint on the possible percentage of errors. Positions 1 and 8 combined yield only $18.0 \%$ of choices. They also have the two lowest proportions of errors. In the other positions, the percentage of choices is low and the percentage of errors high.

It is not the case in any of the other groups that more than half the choices fall on the two middle positions, but these two positions still have a relatively high percentage of the choices in Atkinson's two groups where it is also true that Position 8 is very infrequently selected. Both of these features are more marked in the younger of
Atkinson's groups. Both are absent in Group B, which contains the oldest children.

If the percentage of errors is taken as a criterion of position difficulty, then the order of relative ease is $1,8,2,7,5,4,6,3$ for Group A, 1,8,2,7,6,3,4,5 for Group B, $1,2,8,3,4,5,7,6$ for Group 1, and $1,2,3,8,4,6,5,7$ for Group 2. The Kendall coefficient of concordance (W) for these four rank orders is significant $(p<.01)$. The overall percentage of errors-that is, the proportion of all choices made that were erroneous-varies considerably for the four groups. The figures are: $75.0 \%$ for Group A $57.3 \%$ for Group B; $53.0 \%$ for Group 1; $38.9 \%$ for Group 2.

\section{DISCUSSION}

The claim that the technique described by Atkinson et al is successful in securing the cooperation of young children is not entirely borne out by this study, particularly for the group of Ss most closely correspond. ing in age to those with whom Atkinson worked. This is true even though the children in Edinburgh had to sustain cooperation through only $25 \%$ of the number of trials given to the children in California.

This procedural difference is possibly relevant to the finding of large differences in the overall percentage of errors. The Ss of Atkinson's younger group gave a lower percentage of erroneous first choices than did even the Ss in the older of the two Edinburgh groups. This may be because Atkinson's Ss had four times as many trials and improved with practice, though the effects of fatigue might have been thought likely to counteract any improvement. Hagen \& Kingsley (1968), who used the same method but gave their Ss 16 trials, report that performance on the first 8 trials was significantly better than on the last 8 for Ss aged between 6 and 10 years. They also studied nursery school children but they do not report on this question for the younger group. It is, of course, possible that Atkinson's Ss were generally more advanced than the Edinburgh children. The latter came for the most part from families in relatively poor socio-economic conditions.

The tendency reported by Atkinson et al for their Ss to select the card position just one lower (i.e., more recent) than the correct one is not evident at all in the results for Group A, and while there may be some indication of it in Group B, it is by no means as clear-cut as in Atkinson's data. However, the tendency, more marked in Group A than in Group B, for wrong choices to fall somewhere in the more recent part of the sequence is at least compatible with the suggestion made by Atkinson et al that the children may sometimes search for the right card by "counting back" from the card most recently presented, and may miss out some items, with the result that their count is too low.

If the percentage of Ss responding correctly at each card position is taken as the criterion of success, as it was by Atkinson et al, then the results for Group A support their conclusion that there is no primacy effect in young children, while the results for Group B suggest that in the age-range immediately above the one they studied this effect emerges clearly. However, a major difference between Group A and Group B lies in the distribution of choices (right or wrong) over the eight positions; and when this is allowed for by looking not at the proportion of Ss choosing Position $n$ when $n$ is correct, but rather at the proportion of all choices of $\mathbf{n}$ which are correct choices, then evidence of a primacy effect emerges for Group A also. That is, Position 8 has the highest proportion of correct choices with the exception of Position 1. It appears that Positions 1 and 8 are not preferred positions, but when they are chosen they are more likely than are other positions to be chosen correctly. When this measure of success is used, the three positions with the highest success rates are $1,8,2$, in that order, for both Group A and Group B. In Atkinson's groups, they are $1,2,8$ and $1,2,3$, respectively, but Position 8 is only a little more difficult than Position 3 in the latter instance. So this measure yields, even for the youngest Ss tested, some evidence of greater success at the first-presented position than in the middle of the series, and calls in question the conclusion that the short-term memory of young children differs in some fundamental way from that of older Ss.

The possible interrelationships of (1) percentage of Ss making a correct choice at any given position, (2) percentage of all choices that fall on a given position, and (3) percentage of choices at a given position which are correct choices, are obviously very complex. It could be that certain response configurations would serve to mask a primacy or a recency effect if (3) was used as a criterion of success, just as other response configurations can mask such an effect when (1) is taken as the criterion. It would therefore seem advisable to take account of both measures, especially in attempts to interpret the responses of young children.

\section{REFERENCES}

ATKINSON, R. C., HANSEN, D. N., \& BERNBACH, H. A. Short-term memory with young children. Psychonomic Science, 1964, 1, 255-256.

HAGEN, J. W., \& KINGSLEY, P. R. Labeling effects in short-term memory. Child Development, 1968, 39, 113-121. NOTE

1. This research was supported by a grant from the Scottish Council for Research in Education. Helpful comments from J. F. Reid and R. J. Wales are gratefully acknowledged. 